\title{
Vocativos y tratamientos nominales en tres obras literarias mexicanas de los siglos XIX y XX
}

Vocatives and Nominal Address Terms in Three Mexican Literary Works of the 19th and 20th Centuries

María Eugenia VÁZqueZ LasLOP

RECIBIDO: 12 DE MARZO DE 2020

Centro de Estudios Lingüísticos y Literarios

El Colegio de México

Carretera Picacho Ajusco 20. Ciudad de México, 14110. México

mvazquez@colmex.mx

Orcid ID 0000-0001-9422-8839

Resumen: Se describe el uso de los tratamientos nominales en tres obras literarias mexicanas: dos novelas - Los bandidos de Río Frío (1892-1893), de Manuel Payno, y Los de abajo (1915-1920), de Mariano Azuela- y la versión teatral de Los albañiles (1969), de Vicente Leñero, en función de dos variables gramaticales (los sistemas de segunda persona y la categoría del núcleo del sintagma nominal correspondiente) y dos pragmáticas (la relación interpersonal del hablante con el referente del tratamiento nominal y la valoración que el primero atribuye al segundo). Se observa que el uso de los tratos nominales no sigue un patrón estable en función de estas variables, entre otros factores que intervienen en las situaciones comunicativas, y que es la variabilidad lo más común en el uso, inclusive de un mismo tipo de tratamiento nominal en el dinamismo dialógico. El análisis es descriptivo, de tipo cuantitativo y cualitativo.

Palabras clave: Tratamientos nominales del español. Vocativos nominales. Relaciones interpersonales simétricas y asimétricas. Valoración del hablante al destinatario. Corpus literario.
Abstract: This paper describes the use of Spanish nominal address terms in Mexican literary works: Los bandidos de Río Frío (1892-1893), by Manuel Payno, Los de abajo (1915-1920), by Mariano Azuela, and the play Los albañiles (1969), by Vicente Leñero. The quantitative and qualitative analyses are based on the occurrence of address terms types with two grammatical (Spanish second-person systems and the grammatical category of the corresponding nominal phrase head) and two pragmatic variables (the interpersonal relationship of the speaker with the referent of the address term and the evaluation that the first attributes to the second). It is observed that the use of nominal address terms does not follow a stable pattern based on these variables, among other factors that intervene in communicative contexts. Instead, variability is the most common situation. In addition, the same type of address term may undergo changes in dialogic dynamism.

Keywords: Spanish Nominal Address Terms. Noun Vocatives. Symmetric and Asymmetric Interpersonal Relationships. Speaker's Evaluation of the Addressee. Literary Corpus. 


\section{INTRODUCCIÓN}

E n este trabajo se analizan los tratamientos nominales en tres obras literarias, cuyos autores han llevado a los diálogos el habla popular de México de los siglos XIX y XX: Los bandidos de Río Frío, de Manuel Payno (1892-1893), Los de abajo, de Mariano Azuela (1915), y Los albañiles, de Vicente Leñero (1969).

El objetivo del estudio es explorar el uso de los tratamientos nominales en las tres obras literarias en función de variables gramaticales (la categoría gramatical del núcleo del sintagma nominal y el sistema de segunda persona) y pragmáticas (las relaciones interpersonales de simetría y asimetría y la valoración por parte del hablante del destinatario del trato nominal) y determinar si es posible establecer tendencias generales en este ámbito sintagmático.

Una breve caracterización de los vocativos y los tratamientos nominales del español se expone en $\$ 2$. En $\$ 3$ describo brevemente las características editoriales y estilísticas de las tres obras literarias seleccionadas. $\mathrm{El}$ apartado $\$ 4$ está dedicado a la descripción cuantitativa de los usos de los tratos nominales de las tres obras literarias en función de las variables gramaticales y pragmáticas. A modo de discusión, en $\$ 5$ esbozo algunos aspectos de la variabilidad en el uso de los tratamientos nominales, pues no es posible establecer reglas según sus clases categoriales.

\section{VOCATIVOS Y TRATAMIENTOS NOMINALES DEL ESPAÑOL}

Los vocativos pueden adoptar las formas de los pronombres de segunda persona y los tratamientos nominales. Mientras que las primeras pueden describirse en términos paradigmáticos, los segundos presentan una mayor diversidad al pertenecer sus elementos léxicos a categorías abiertas. De hecho, el vocativo en general, desde el punto de vista tipológico, se caracteriza en términos sintagmáticos -aun cuando cuente con una marca morfológica-, por ejemplo, por su posición y su no integración prosódica y sintáctica en el enunciado y en la estructura oracional (Noel Aziz Hanna/Sonnenhauser 283-84). De tal manera que es necesario establecer parámetros de uso para comprender su sistematicidad, la cual dependerá de las propiedades específicas de la lengua en cuestión.

En español, los vocativos son sintagmas nominales -con un núcleo pronominal, un nombre propio, un nombre común (NGLE \$32.2g) o un adjetivo (Espinal 114)-, ${ }^{1}$ cuyo significado es señalar y apelar (NGLE $\$ 42.13 \mathrm{r}$ ) a un inter-

1. Añadiría: un adjetivo que no esté cumpliendo una función predicativa, como en foven, pase por aquí. 
locutor (tienen una función deíctica) e identificar a alguien (Fernández Leborans $\$ 2.3 .2 .2$; Espinal 116-18). ${ }^{2}$ A diferencia de los sintagmas nominales referenciales en enunciados declarativos y exclamativos, los sintagmas nominales en enunciados vocativos carecen de artículo definido -aunque sí admiten posesivos, complementos y aposiciones-, pueden ir acompañados de una interjección, su posición en el enunciado tiene algunas restricciones y, al no estar integrados a la oración, no son complementos sintácticos ni semánticos del predicado (Alonso-Cortés $\$ 62.8 .5 .3$; NGLE $\$ 32.2 \mathrm{j}$; $\$ 42.13 \mathrm{u}$ ).

Las motivaciones de los estudios acerca de los tratamientos nominales son muy diversas. ${ }^{3}$ En las gramáticas, por ejemplo, destacan las anotaciones de Fontanella de Weinberg (\$22.6) respecto de las relaciones diádicas y los tipos semánticos de estas formas, con un breve catálogo de tratamientos nominales en algunas ciudades de Iberoamérica. Alonso-Cortés dedica el apartado $\$ 62.8 .5 .2$ a las "clases de nombres empleados como vocativos". Morera clasifica la idiomaticidad de los apodos e hipocorísticos del español y describe sus aspectos morfológicos. Otros estudios se enmarcan en el mundo de la antroponimia, como, por ejemplo, para el español de México, los de Báez Pinal, Boyd-Bowman (1955; 1970), Estrada, Herrera Lima/Mendoza y Miquel i Vergés. Otras investigaciones emanan del Atlas linguiistico de México (Lope Blanch 1996) acerca de los tratamientos con nombres comunes identificados a partir del cuestionario de Lope Blanch (1970) (ver Vázquez Laslop/Orozco). Desde otras perspectivas, existe interés en los cambios categoriales de tratos con nombres comunes cuando, de origen, son apelativos insultantes: en el proceso de cambio, primero, mutan su valor negativo a uno positivo, como marcas de identidad y pertenencia a un grupo social, van perdiendo su capa-

2. A veces también una función predicativa, como en ;Tú, niño!, donde niño es una predicación del referente. Desde el punto de vista de Espinal (115) el verdadero vocativo en este caso es tú y niño es un vocativo falso (fake vocative), pues solo el primero cumple con la función deíctica y referencial. Un vocativo con nombre propio o con nombre común puede cumplir también con las funciones deíctica y referencial, como en ifuan, ven! o en ;Ey, muchacho!

3. De hecho, la bibliografía acerca de los tratamientos del español en general ha aumentado considerablemente en las últimas décadas, tal como se corrobora en la relación bibliohemerográfica de Fernández/Gerhalter. Uno de los evaluadores del presente artículo bien ha observado que en esta sección se podría ampliar la bibliografía de las formas gramaticales y nominales de tratamiento a todo el ámbito americano e incluso a siglos previos a los considerados en esta investigación. No obstante, además de que las limitaciones de espacio nos impiden ofrecer una revisión exhaustiva del tema en Hispanoamérica, el brevísimo recuento bibliográfico de esta sección tiene como único objetivo delimitar la línea temática y metodológica de este artículo, con énfasis en los pocos estudios acerca de los tratamientos nominales del español de México. Ver también Vázquez Laslop/Orozco. 
cidad referencial y deíctica, para terminar como marcadores discursivos e interjecciones o pronombres impersonales. En el español de México pueden citarse las investigaciones de Palacios y de Kleinknecht, aunque este fenómeno parece ser común a otras variantes del español (por ejemplo, Ramírez Gelbes/Estrada; Helincks) y otras lenguas, como el inglés (Palacios Martínez; Rendle-Short).

Son escasas, sin embargo, las investigaciones de los tratamientos nominales del español en relación con su ámbito de enunciación. Al respecto, un estudio innovador es el de Alba de Diego y Sánchez Lobato, quienes exploran la relación entre el sistema de segunda persona y los tipos de tratamientos nominales con las clases de las relaciones interpersonales, a la luz de los ejes del poder y la solidaridad (Brown/Gilman). En el desarrollo de esta perspectiva sociolingüística y pragmática, las investigaciones de los tratamientos nominales del español de México se han centrado en datos de la Ciudad de México: Kim Lee documenta, a partir de cuestionarios, los tratos nominales de jóvenes en los ámbitos familiar, de amistad y laboral, y Cepeda Ruiz incorpora en su estudio formas pronominales y nominales empleadas en la Ciudad de México con datos de los siglos XX y XXI, extraídos de entrevistas semidirigidas de corpus orales existentes y de cuestionarios.

Entran en el grupo de los estudios en los que se observan los tratos nominales en la interacción interpersonal los trabajos de Pedroviejo Esteruelas y Calderón Campos, quienes analizan, entre otras cosas, las correlaciones entre los sistemas de segunda persona y los tratamientos nominales en obras de teatro.

El presente estudio se ubica en esta última línea. Se describe el uso de los tratamientos nominales en tres obras literarias mexicanas en función de dos variables gramaticales -la categoría del sintagma nominal y la concurrencia del trato nominal con el sistema de segunda persona- y dos variables pragmáticas -las relaciones interpersonales de simetría y asimetría y la valoración que imprime el hablante al destinatario con el trato nominal-. La atención principal de la investigación está en la función vocativa de los tratamientos nominales. No obstante, dado que el ámbito de la apelación abarca también estrategias indirectas, con la tercera persona, se incluyen en el corpus algunas ocurrencias de tratamientos nominales en la dimensión del hecho relatado (Jakobson 133), cuando se emplean de manera prodemostrativa o prodeíctica (Bühler n. 1, 147; Hammermüller 514), y cuando el autor describe el tratamiento nominal que recibe algún personaje que actúa como interlocutor en algún diálogo. 


\section{TRES OBRAS LITERARIAS MEXICANAS DE LOS SIGLOS XIX Y XX}

Las obras literarias seleccionadas reflejan variantes del español de México. De todas formas, no es el objetivo de este trabajo caracterizar los tipos y los usos particulares de los tratamientos nominales en el habla mexicana, sino describir el uso de determinados tipos de tratamientos nominales según variables que apuntan a la variación diafásica y diastrática.

\subsection{Los bandidos de Río Frío, de Manuel Payno}

Manuel Payno (1820-1894) escribió Los bandidos de Río Frío entre 1888 y 1891 como novela por entregas (Olea Franco 105), y como libro, editado por Juan de la Fuente Parres, en 1892-1893. Payno fue uno de los principales representantes del México decimonónico y se desempeñó tanto en la política como en la creación literaria. Como señala Olea Franco, en Los bandidos de Río Frío, Payno "quiso compendiar el panorama social, cultural, político y lingüístico del México del siglo XIX que había conocido" (106-07). Su riqueza se despliega en la variedad de sus personajes de todos los estratos sociales, de su origen rural o urbano, de sus edades y de sus relaciones a veces íntimas, a veces casuales, a veces tangenciales de las que van surgiendo sus múltiples historias. Pero tal riqueza abarca también la diversidad lingüística tanto de estilos de habla reflejada en sus diálogos cuanto en su léxico regional y en la glosa de algunas de sus voces plasmada en notas al pie de página del propio Payno.

La novela se estructura en dos partes, la primera, con 54 capítulos y la segunda, con 63. Reviso para el corpus de los tratamientos nominales la edición de la Secretaría de Cultura de 2016, basada en la edición preparada por Manuel Sol en 2000.

\subsection{Los de abajo, de Mariano Azuela}

Mariano Azuela (1873-1952) es el autor de Los de abajo, novela publicada en 1915 primero por entregas y luego, ese mismo año, como libro. Poco después, el propio Azuela hizo una revisión profunda de la obra y la volvió a publicar en 1920 en la Tipográfica Razaster, además de con correcciones de todo tipo, con pasajes y personajes añadidos. Se la ha catalogado como una obra con "cualidades de realismo literario" (Díaz Arciniega 12), que retrata de forma verosímil escenas de la lucha armada de la Revolución mexicana de 1910. La 
novela refleja la perspectiva de "los de abajo", según destaca Jiménez de Báez (844), como un cuestionamiento de la estructura del poder. Desde el punto de vista literario, se la considera innovadora, entre otras cosas, por su "brevedad y fragmentarismo" y "su uso literario de un lenguaje popular" (Olea Franco 172). Al respecto, Olea Franco resalta con las palabras de Xavier Villaurrutia lo literariamente revolucionario de Azuela, pues con ello este abrió nuevas tendencias en la narrativa mexicana: "Unas cuantas frases y ya estamos respirando en un ambiente; unas cuantas líneas que duran solo un segundo, y ya está, en pie, un personaje, y así otro y otros" (Villaurrutia 57; citado por Olea Franco 173; ver Díaz Arciniega 71-72).

Mariano Azuela era médico cuando decidió convivir con los revolucionarios en la lucha armada para emprender su aventura novelesca. Conoció en esas circunstancias a personajes provenientes del medio rural del norte de México y pudo empaparse de su modo particular de hablar (Díaz Arciniega 32). Según señala Olea Franco (178), Azuela hace patente la diferencia de estilos en el "doble registro" de la novela: por un lado, la voz del narrador, que refleja el habla culta, y, por otro, la voz de los personajes en los diálogos, con su expresión lingüística popular retratada en una "oralidad fingida" que -desde el punto de vista de Olea Franco (190)- hace de Azuela uno de los "grandes maestros" de esta ilusión literaria.

Los tratamientos nominales seleccionados de Los de abajo para este estudio provienen en su mayor parte de los diálogos. Tomo la edición de 2015 conmemorativa de los 100 años de la primera publicación de la novela, preparada por Víctor Díaz Arciniega, quien decidió basarse en la versión revisada por Azuela en 1920, con cambios que, según el propio editor, rescatan el lenguaje original, que había quedado desdibujado (Díaz Arciniega 88).

\subsection{Los albañiles, de Vicente Leñero}

Los albañiles, de Vicente Leñero (1933-2014), se publicó como novela en 1964, premiada por la editorial Seix-Barral. Aunque se la podría catalogar como una novela policiaca, en realidad no parece cumplir del todo con los cánones de este género (Szmetan 67). La novela se estructura alrededor de los interrogatorios de un detective que investiga a los posibles responsables del asesinato de un velador en una construcción en la ciudad de México, quienes rememoran experiencias con la víctima y el resto de los personajes, solo que seguir esta lógica no resulta transparente para el lector. Leñero yuxtapone los hechos, los 
pensamientos y los personajes de manera fragmentada, dislocada y sin un orden cronológico determinado, creando así distintos planos de la realidad que se desarrollan simultáneamente (Robles 583). El lector llega al punto de no lograr identificar qué es verdad y qué es ilusión, sin dejar de percibir la verosimilitud de lo que se le va presentando; además de no revelar al asesino, la novela culmina con la incertidumbre misma de si existió un asesinato. Por ello, Schlickers, junto con Ludmer, destaca el carácter polifacético de la novela, la cual puede leerse "en varios niveles: «es a la vez psicológica, sociológica, simbólica, mítica»” (Ludmer 208, citada por Schlickers 367).

Para la selección de los tratamientos nominales del presente estudio, he acudido a la versión teatral de Los albañiles escrita por el mismo Leñero en 1969. ${ }^{4}$ Tomo la edición del Teatro completo del autor, publicada por el Fondo de Cultura Económica en 2008. Leñero reproduce de manera convincente el estilo de habla de cada personaje, según su condición social, en conversaciones cotidianas, mundo que el autor conoce, tal vez porque estudió Ingeniería Civil, pero terminó dedicándose al periodismo y la escritura literaria.

\section{Los tratamientos nominales en Los bandidos de Río Frío, LOS DE ABAFO Y LOS ALBAÑILES}

A modo de recuento simple del uso de los tratamientos nominales en las obras literarias seleccionadas en función de su categorización gramatical y pragmática, en $\$ 4.1$ se describe el corpus y los criterios de selección y categorización gramatical de los ítems y, en $\$ 4.2$, se da cuenta de la distribución de estos según su concurrencia con los sistemas de segunda persona, las relaciones de simetría y asimetría entre los participantes y la valoración que el hablante atribuye al destinatario del tratamiento nominal.

\subsection{Corpus}

Un primer corpus se constituye de 415 tratamientos nominales recogidos de Los bandidos de Río Frío (capítulos 1 al 47 de la primera parte), de Los de abajo y de la versión teatral de Los albañiles (en adelante, Bandidos, Abajo y Albañiles). De cada obra se seleccionaron todos los tratamientos nominales distintos en función de sus referentes y de la variación morfosintáctica de los sintagmas

4. En 1976 se hizo una versión cinematográfica, dirigida por Jorge Fons. 
nominales correspondientes. Este criterio requiere de algunas aclaraciones. Por un lado, entiendo por referente la entidad animada significada por el tratamiento nominal, sea humana, suprahumana o animal y sea individual o colectiva. El referente puede o no ser el oyente y puede o no estar presente en la situación comunicativa; es decir, el referente no siempre es un participante del hecho discursivo, sino que puede ser un participante del hecho relatado (Jakobson 133). ${ }^{5}$ Por otro lado, cada ítem se corresponde con un sintagma nominal diferente empleado para llevar a cabo el acto apelativo o el acto de referencia. Por ejemplo, en (1) la Pintada apela a Margarito con tres sintagmas nominales diferentes en su súplica de ayuda ante la orden de Demetrio. Cada uno de ellos se seleccionó como un ítem de tratamiento nominal (güero Margarito, güero de mi vida y güerito de mi corazón). No obstante, si la Pintada en otra ocasión se volvía a dirigir a Margarito con alguno de estos tratamientos, este ya no se incluía en el corpus.

(1) Tres tratamientos nominales para un mismo referente

Y la Pintada insultó a Camila, a Demetrio, a Luis Cervantes y a cuantos le vinieron a las mientes, con tal energía y novedad, que la tropa oyó injurias e insolencias que no había sospechado siquiera.

Demetrio esperó largo rato con paciencia; pero como ella no diera trazas de acabar, con mucha calma dijo a un soldado:

-Echa fuera esa borracha.

- ¡Güero Margarito! ¡Güero de mi vida! ¡Ven a defenderme de éstos...! ¡Anda, güerito de mi corazón!... ¡Ven a enseñarles que tú eres hombre de veras y ellos no son más que unos hijos de...! (Abajo 2/12/225/ $3617-3628)^{6}$

Un mismo tratamiento nominal puede emplearse para distintos referentes. Según el criterio adoptado, cada ocurrencia de estos casos se seleccionó como ítem del corpus. El uso frecuente de amigo es un ejemplo de ello. En (2a) el detective Munguía se dirige a Sergio García en el interrogatorio con amigo. En (2b) el mismo detective emplea amigo para responderle a un desconocido. Las dos ocurrencias de amigo se seleccionaron como ítems del corpus.

5. Un ejemplo de ello es cuando don Jesús, un pulquero, se dirige a Evaristo, un cliente, y le advierte: "Es que tendrá que habérselas con algunos muy listos. No dejarán de venir hoy el Tuerto Cirilo, Vicente la Chinche y mi tocayo Chucho el Garrote" (Bandidos 214; cursivas mías).

6. El código de Abajo indica Parte/Capítulo/Página/Líneas. 
(2) Usos de amigo para distintos referentes

a. SERGIO: No es cierto. Yo no odiaba a don Jesús. [...] MUNGUÍA: [...] ¿Es cierto que era un lépero? SERGIO: Sí, señor. MUNGUíA: ¿Lépero en qué sentido? ¿Decía malas palabras?... ¿Usted nunca ha dicho malas palabras, amigo García? ¿Nunca ha mandado a nadie a la chingada, así, con todas sus letras?... No se ponga colorado. Está bien, nunca ha dicho malas palabras. ¿Por qué? (Albañiles 1/416-423/078/0676-0687)

b. EL HOMBRE: ¿Buscaba a alguien?

MUNGUÍA: ¿Es usted el velador de este edificio?

EL HOMBRE: ¿Qué se le ofrece?

MUNGUía: Nada. [...] Nada, amigo. (Albañiles 2/378-381/105-106/ 1497-1501)

Por último, un tratamiento nominal puede ocurrir en variantes morfosintácticas como las de los ejemplos en (3a-e). Cada una de ellas -señá, ña, seña, señora, señor amo, el siñor- se seleccionó para integrarse al corpus. ${ }^{8}$

(3) Variantes de señor/señora

a. -Ande, pos si aquí está usté también, señá Pachita..., no la había visto...

-Güenos días le dé Dios, ña Fortunata... ¿Cómo amanecieron? (Abajo 1/09/124/0885-0888)

b. Esta viejecita, que se llamaba Anastasia y le decían seña Nastasita, estaba arrimada en una atolería del callejón de la Condesa. (Bandidos 1/10/114/2883-2885) ${ }^{9}$

c. -¿Cuál es el parecer de usted, señora Robreño? (Bandidos $1 / 28 / 329 / 9128)$

d. -Sí, señor amo, lo que quiera Su Mercé. (Bandidos 1/08/94/2320)

7. El código de los ejemplos de Albañiles indica Acto/Núm. de turno(s)/Página/Líneas.

8. En este mismo volumen se ofrecen las claves evolutivas del título señor en el español europeo quinientista (Calderón Campos \$5.2) y aurisecular (Iglesias Recuero y Medina Morales/LópezVallejo $\$ \$ 3.1$ y 6.3.2, respectivamente). Además, Rivadeneira Valenzuela (\$3.2.1) atestigua el mismo título social (señor) para dirigirse a la divinidad en el español chileno del XVIII. Para el femenino señora y sus patrones de construcción en las épocas clásica y moderna, ver Kluge (\$4.1) y García-Godoy (\$5.2), respectivamente.

9. El código de Bandidos indica Parte/Capítulo/Página/Línea(s). 
e. -[...] Si el siñor quisiera darme una armita...

-Rifle no queda, hermano; pero esto de algo te ha de servir. ( $A b a$ jo 1/16/153-154/1700-1703)

Bajo estos criterios, el corpus se compone de 415 tratamientos nominales, 218 extraídos de Bandidos, 125 de Abajo y 72 de Albañiles. En la tabla 1 se presenta una primera clasificación según la categoría del núcleo del sintagma nominal.

\begin{tabular}{c|c|c|c|c|c|c} 
& \multicolumn{2}{|c|}{ Bandidos } & \multicolumn{2}{c|}{ Abajo } & \multicolumn{2}{c}{ Albañiles } \\
\cline { 2 - 7 } & FreCUENCIA & $\%$ & FrECUENCIA & $\%$ & FrECUENCIA & $\%$ \\
\hline Nombre propio & 78 & 35.8 & 43 & 34.4 & 24 & 33.3 \\
\hline Nombre común & 101 & 46.3 & 52 & 41.6 & 32 & 44.4 \\
\hline Adjetivo & 39 & 17.9 & 30 & 24.0 & 16 & 22.2 \\
\hline \multicolumn{1}{c|}{ Total } & 218 & 100 & 125 & 100 & 72 & 99.9 \\
\hline
\end{tabular}

Tabla 1. Total de tratos nominales por obra $(\mathrm{N}=415)$.

Desde esta primera caracterización se observa que la distribución porcentual de los tratamientos nominales por el núcleo categorial de los sintagmas correspondientes es muy similar en cada obra, lo cual se percibe en la gráfica 1, con los porcentajes de la tabla 1.

Corpus en porcentajes $(\mathrm{N}=415)$

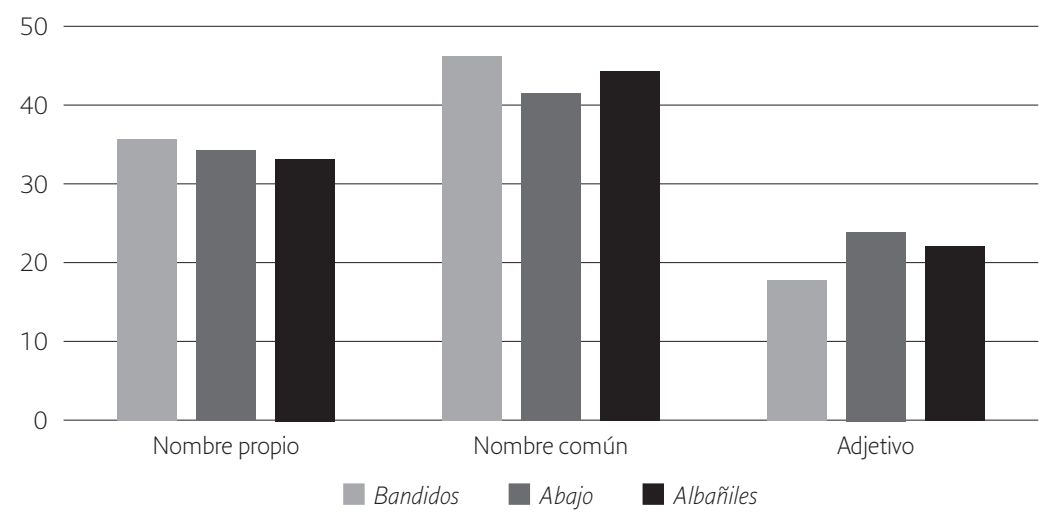

Gráfico 1. Porcentajes de los tratos nominales por núcleo categorial y por obra $(\mathrm{N}=415)$. 
Sin embargo, en una categorización más detallada, la distribución de los tipos de tratamientos nominales en las tres obras pierde su similitud. En la tabla 2 se observa que existe cierta similitud en los porcentajes de hipocorísticos (sean solos, con un título, con apodo o con apellido), de nombre de pila + apodo y de nombre de pila + apellido, no así en el resto de las categorías de los tratos nominales.

\begin{tabular}{l|c|c|c|c|c|c}
\multirow{2}{*}{ Tratos nominales } & \multicolumn{2}{|c|}{ Bandidos } & \multicolumn{2}{|c|}{ Abajo } & \multicolumn{2}{c}{ Albañiles } \\
\cline { 2 - 7 } & FreCuenCIA & $\%$ & FreCUENCIA & $\%$ & FreCUENCIA & $\%$ \\
\hline Pila & 31 & 14.2 & 10 & 8.0 & 9 & 12.5 \\
\hline Nombre común & 58 & 26.6 & 62 & 49.6 & 30 & 41.7 \\
\hline Título & 53 & 24.3 & 8 & 6.4 & 10 & 13.9 \\
\hline Posesivo + nombre & 19 & 8.7 & 11 & 8.8 & - & - \\
\hline Título + pila & 29 & 13.3 & 11 & 8.8 & 3 & 4.2 \\
\hline Hipocorístico & 6 & 2.8 & 2 & 1.6 & 2 & 2.8 \\
\hline Título + hipocorístico & 3 & 1.4 & - & - & - & - \\
\hline Apodo & 11 & 5.0 & 10 & 8.0 & 9 & 12.5 \\
\hline Apellido & 1 & 0.5 & 3 & 2.4 & 5 & 6.9 \\
\hline Pila + apodo & 2 & 0.9 & 1 & 0.8 & - & - \\
\hline Título + apellido & 2 & 0.9 & 3 & 2.4 & 4 & 5.6 \\
\hline Título + pila + apellido & 1 & 0.5 & 2 & 1.6 & - & - \\
\hline Hipocorístico + apodo & 1 & 0.5 & - & - & - & - \\
\hline Hipocorístico + apellido & 1 & 0.5 & - & - & - & - \\
\hline Pila + apellido & - & - & 2 & 1.6 & - & - \\
\hline \multicolumn{1}{|c|}{ Total } & 218 & 100 & 125 & 100 & 72 & 100 \\
\hline
\end{tabular}

Tabla 2. Categorías de los tratamientos nominales en las tres obras.

Se observa, además, en la tabla 2, que no todos los tipos de tratos nominales ocurren en las tres obras. Para los fines de este estudio, se hace el contraste de aquellas categorías de tratos nominales que ocurrieron en las tres: nombre de pila, nombre común, título, título + nombre de pila, hipocorístico, apodo, apellido y título + apellido. Como resultado de esta criba, el total de casos analizado es de 372: 191 en Bandidos, 109 en Abajo y 72 en Albañiles. 


\subsection{Los tratamientos nominales en las tres obras según variables gramaticales y pragmáticas}

La pregunta central es si existen tendencias de uso de los tratamientos nominales similares entre Bandidos, Abajo y Albañiles en función de determinadas variables gramaticales y pragmáticas. De entrada, se ha comprobado que, de hecho, este es el caso si el núcleo categorial de los sintagmas nominales es un nombre propio, un nombre común o un adjetivo (v. tabla 1 y gráfico 1). En los siguientes párrafos se presenta la distribución de los 372 tratamientos nominales por obra literaria en función del sistema de segunda persona con el que concurren (\$4.2.1), la relación de simetría o asimetría y de cercanía o distancia que el hablante establece con la entidad referida por el tratamiento nominal (\$4.2.2) y la valoración que el hablante imprime en dicha relación $(\$ 4.2 .3)$.

La presentación de los resultados cuantitativos se organiza en tablas comparativas entre las tres obras literarias, con el objeto de apreciar de manera general la variedad de categorías de los tratos nominales según su distribución por cada factor y su contraste entre las tres obras. Se añade el número de ocurrencias por factor y, entre paréntesis, el porcentaje correspondiente a la distribución de las ocurrencias por factor. Se destacan con cursivas las frecuencias más altas por categoría de trato nominal.

\subsubsection{Los tratamientos nominales y el sistema de segunda persona}

En la tradición gramatical (Fontanella de Weinberg; NGLE), así como en las teorías psicosociales (Brown/Gilman), en las pragmáticas, como las de la cortesía verbal (Brown/Levinson) o culturales (Scollon/Scollon/Jones), se suele identificar el uso del sistema tuteante con el trato solidario, de confianza, de cercanía e informal. Alba de Diego y Sánchez Lobato (104), por su parte, asocian el uso del nombre propio, el hipocorístico y el apodo con esta clase de tratamiento. En cambio, el sistema de tratamiento no solidario o de poder, formal y de distancia se identifica con el uso de usted, al que Alba de Diego y Sánchez Lobato añaden, según si el hablante es un superior respecto del destinatario, el "nombre propio" (nombre de pila) o "términos más específicos", como el apellido o nombres como bijo, joven, etc., mientras que si el hablante es un inferior respecto del destinatario, aquel empleará, según dichos autores, títulos genéricos, términos de pa- 
rentesco o, en función de su clase social, un título + nombre de pila o apellido. ${ }^{10}$

Sin todavía entrar en los detalles de las relaciones simétricas o asimétricas entre los interlocutores (\$4.2.2), en la tabla 3 organizo la distribución de los tratamientos nominales aplicados al referente en las tres obras literarias, según si concurren con el tuteo $(T)$, el trato de usted $(V)$ o con ninguno de ellos (NA, por 'no se aplica'). Los cruces de estas variables y sus factores se leen de la siguiente manera. Por ejemplo, en Bandidos el $100 \%$ de los hipocorísticos se distribuyó en combinación con cuatro usos de tú (66.7 \%) y con dos usos en los que no ocurrió la segunda persona (NA; $33.3 \%$ ). Resalto en cursivas los porcentajes más altos según cada categoría del trato nominal.

En las tres obras, el título suele asociarse al trato de usted y el nombre de pila, al tuteo, aunque en Abajo esta categoría fue igualmente frecuente con el trato de usted (50\%, en ambos sistemas). También puede decirse que el título + apellido no ocurrió con el tuteo, pero no siempre con usted, pues en Bandidos los dos únicos casos no coincidieron con la segunda persona. El nombre común se registró con segunda persona en las tres obras, pero sin coincidir en los tratos de tú o de usted: en Bandidos y en Albañiles fue más frecuente con tú, mientras que en Abajo, con usted, pero no con una diferencia pronunciada respecto de su uso con tú ( $37.1 \%$ y $32.3 \%$, respectivamente). La aparición de apodos e hipocorísticos no es muy común y tampoco se observa una regularidad en su uso con alguno de los sistemas de segunda persona. De hecho, en Bandidos, los casos de apodos solo se registraron en enunciados en otra persona gramatical.

\begin{tabular}{|c|c|c|c|}
\hline OBRA $^{T / V}$ & Tú & Usted & NA \\
\hline Bandidos* & $\begin{array}{l}\text { N. común - } 28(48.3 \%) \\
\text { Título }-3(5.7 \%) \\
\text { Tít. + pila - } 5(17.2 \%) \\
\text { Pila - } 27(87.7 \%) \\
\text { Hipoc. }-4(66.7 \%)\end{array}$ & $\begin{array}{l}\text { N. común - } 9 \text { (15.5 \%) } \\
\text { Título - } 27(50.9 \%) \\
\text { Tít. + pila - } 12(41.4 \%) \\
\text { Apodo - } 1(9.1 \%)\end{array}$ & $\begin{array}{l}\text { N. común - } 17(29.3 \%) \\
\text { Título - } 21(39.6 \%) \\
\text { Tít. + pila - } 12(41.4 \%) \\
\text { Apodo - } 10(90.9 \%) \\
\text { Pila }-4(12.9 \%) \\
\text { Hipoc. }-2(33.3 \%) \\
\text { Tít. + apell. }-2(100 \%) \\
\text { Apellido-1 (100\%) }\end{array}$ \\
\hline
\end{tabular}

10. Brown y Ford, acerca de los tratamientos nominales del inglés, llevan a cabo un análisis por díadas, en función de las relaciones interpersonales del poder y la solidaridad, y llegan a proponer que los patrones que encuentran son de carácter universal. 


\begin{tabular}{|c|c|c|c|}
\hline Abajo** & $\begin{array}{l}\text { N. común - } 20 \text { (32.3\%) } \\
\text { Título - } 2 \text { (25\%) } \\
\text { Tít. + pila - } 1(9.1 \%) \\
\text { Apodo - 6(6o\%) } \\
\text { Pila-5 } 50 \%) \\
\text { Apellido - } 1 \text { (33.3\%) }\end{array}$ & $\begin{array}{l}\text { N. común }-7(37.1 \%) \\
\text { Título }-4(50 \%) \\
\text { Tít. + pila }-7(63.6 \%) \\
\text { Pila - } 5(50 \%) \\
\text { Apellido }-1(33.3 \%) \\
\text { Tit. + apell. - 3(100\%) }\end{array}$ & $\begin{array}{l}\text { N. común - } 23 \text { (11.3\%) } \\
\text { Título - } 2 \text { (25 \%) } \\
\text { Tít. + pila - } 3(27.3 \%) \\
\text { Apodo - } 3(30 \%) \\
\text { Hipoc. - } 2(100 \%) \\
\text { Apellido - } 1(33.3 \%)\end{array}$ \\
\hline Albañiles & $\begin{array}{l}\text { N. común - } 15 \text { (50\%) } \\
\text { Título - } 1(10 \%) \\
\text { Apodo- 6(66.7\%) } \\
\text { Pila-7 } 77.8 \%) \\
\text { Hipoc. }-1(50 \%) \\
\text { Apellido-3(60\%) }\end{array}$ & $\begin{array}{l}\text { N. común - } 9(30 \%) \\
\text { Título - 6 (6o \%) } \\
\text { Tít. + pila - } 1 \text { (33.3\%) } \\
\text { Apodo - } 1(11.1 \%) \\
\text { Pila - } 1(11.1 \%) \\
\text { Apellido - } 1 \text { (20\%) } \\
\text { Tít. + apell. - 3(75\%) }\end{array}$ & $\begin{array}{l}\text { N. común - } 6 \text { (20\%) } \\
\text { Título - } 3(30 \%) \\
\text { Tít. + pila - } 2 \text { (66.7\%) } \\
\text { Apodo - } 2(22.2 \%) \\
\text { Pila - } 1(11.1 \%) \\
\text { Hipoc. - } 1(50 \%) \\
\text { Apellido - } 1 \text { (20\%) } \\
\text { Tít. + apell. - } 1 \text { (25\%) }\end{array}$ \\
\hline
\end{tabular}

* Cuatro casos de nombre común (6.9 \%) y uno de posesivo + nombre $(5.3 \%)$ con ustedes; dos casos de título $(3.8 \%)$ con vos.

** Doce casos de nombre común (19.4 \%) con ustedes; un caso de apodo (10 \%) con ustedes.

Tabla 3. Categorías de tratos nominales y sistema de segunda persona en cada obra.

4.2.2 Tratamientos nominales y relaciones interpersonales de simetría y asimetría

Las relaciones entre los participantes en las tres obras literarias se organizan según dos parámetros: las relaciones jerárquicas y las de distancia entre el hablante, el oyente y el referente (como aludido en el hecho relatado; ver $\$ 4.1$, supra) del tratamiento nominal. Las primeras se especifican en los niveles superior, inferior e igual y las segundas en intimidad, cercanía y lejanía. En este estudio tomo la relación del destinatario del trato nominal con el hablante; por ejemplo, el destinatario del tratamiento nominal es un superior íntimo del hablante o un igual cercano al hablante, etc. Por la complejidad que se genera entre estos dos parámetros y las categorías de los tratos nominales, expongo los resultados de cada obra literaria en las tablas 4 (Bandidos), 5 (Abajo) y 6 (Albañiles). De cada una de ellas resalto en cursivas los porcentajes de uso más altos de cada categoría de los tratos nominales. 


\begin{tabular}{|c|c|c|c|}
\hline $\begin{array}{l}\text { DISTANCIA } \\
\text { JERARQuía }\end{array}$ & Íntimo & Cercano & Lejano \\
\hline Superior & $\begin{array}{l}\text { N. común - } 1 \text { (1.7\%) } \\
\text { Título - } 2(3.8 \%) \\
\text { Tit. + pila - } 6 \text { (20.7\%) } \\
\text { Pila - } 1 \text { (3.2\%) } \\
\text { Hipoc. - } 1 \text { (16.7\%) }\end{array}$ & $\begin{array}{l}\text { N. común - } 2(3.4 \%) \\
\text { Título - } 24(45.3 \%) \\
\text { Tít. + pila }-12(41.4 \%) \\
\text { Pila - } 3(9.7 \%)\end{array}$ & $\begin{array}{l}\text { N. común - } 6(10.3 \%) \\
\text { Título - } 15(28.3 \%)\end{array}$ \\
\hline Inferior & $\begin{array}{l}\text { N. común - } 3(5.2 \%) \\
\text { Pila - } 2 \text { (6.4\%) }\end{array}$ & $\begin{array}{l}\text { N. común - } 24(41.4 \%) \\
\text { Título - } 3(5.7 \%) \\
\text { Tít. + pila - } 4(13.8 \%) \\
\text { Apodo - 5 (45.4\%) } \\
\text { Pila - } 17(54.8 \%) \\
\text { Hipoc. - } 2(33.3 \%) \\
\text { Apellido- } 1(100 \%) \\
\text { Tít. + apell. - 2(100\%) }\end{array}$ & $\begin{array}{l}\text { N. común - } 10 \text { (17.2\%) } \\
\text { Título - } 4 \text { (7.5\%) } \\
\text { Tít. + pila - } 5(17.2 \%) \\
\text { Apodo - } 1(9.1 \%)\end{array}$ \\
\hline Igual & $\begin{array}{l}\text { N. común - } 1 \text { (1.7\%) } \\
\text { Pila - } 7 \text { (22.6\%) } \\
\text { Hipocor. - } 1 \text { (16.7\%) }\end{array}$ & $\begin{array}{l}\text { N. común - } 11 \text { (19\%) } \\
\text { Título - } 4 \text { (7.5\%) } \\
\text { Tít. + pila - } 2 \text { (6.9\%) } \\
\text { Pila - } 1 \text { (3.2\%) }\end{array}$ & \\
\hline
\end{tabular}

Tabla 4. Categorías de tratos nominales según la relación del referente con el hablante en Bandidos. ${ }^{11}$

Las tres obras presentan pocas coincidencias respecto de este cruce de variables, pero pueden comentarse algunas. En cuanto a las categorías de los tratos nominales, la máxima variedad en las tres obras se encuentra en el tratamiento del destinatario en sus relaciones de cercanía con el hablante. Particularmente, en la relación de cercano inferior se usó el nombre común, el título solo o con apellido, el apodo y el nombre de pila en distintas proporciones. Es más difícil identificar coincidencias en el ámbito de relaciones sociales donde menos tratamientos nominales se emplearon, aunque sí puede afirmarse que el trato a destinatarios superiores lejanos fue escaso y, en las tres obras, se empleó el título para este tipo de relación. A propósito, la categoría de título fue la más frecuente para destinatarios superiores cercanos. Por su parte, el hipocorístico en las tres obras se usó para relaciones de igualdad, ya sea de intimidad (Bandidos y Albañiles) o de cercanía (Abajo). El apodo también fue preferente en las relaciones de cercanía: en Abajo, para destinatarios iguales, en

11. De 8 casos no fue posible identificar el tipo de relación: 1 título, 2 hipocorísticos y 5 apodos. 
Bandidos, para inferiores y en Albañiles, para iguales e inferiores, con la misma frecuencia. El nombre común nunca fue la categoría más frecuente en las relaciones de intimidad: en Bandidos y Albañiles se dirigió, sobre todo, a inferiores cercanos y en Abajo, a inferiores lejanos. Al contrario, el nombre de pila y el hipocorístico nunca ocurrieron en las relaciones de lejanía -aunque el título + nombre de pila sí se llegó a usar dentro de esta categoría en Bandidos.

\begin{tabular}{|c|c|c|c|}
\hline $\begin{array}{l}\text { DISTANCIA } \\
\text { JERARQUÍA }\end{array}$ & Íntimo & Cercano & Lejano \\
\hline Superior & & $\begin{array}{l}\text { N. común - } 3(4.8 \%) \\
\text { Título - 4 (50\%) } \\
\text { Título + pila - } 4 \text { (36.4\%) } \\
\text { Apodo - } 1 \text { (10\%) }\end{array}$ & $\begin{array}{l}\text { N. común - } 11 \text { (17.7\%) } \\
\text { Título - } 2 \text { (25 \%) }\end{array}$ \\
\hline Inferior & & $\begin{array}{l}\text { N. común - } 7(11.3 \%) \\
\text { Título - } 2 \text { (25\%) } \\
\text { Tít. + pila - } 1(9.1 \%) \\
\text { Apodo - } 2(20 \%) \\
\text { Pila - } 1(10 \%) \\
\text { Apellido - } 2(66.7 \%) \\
\text { Tít. + apell. - } 1(33.3 \%)\end{array}$ & N. común- $23(37.1 \%)$ \\
\hline Igual & Pila - 1 (10\%) & $\begin{array}{l}\text { N. común }-8(12.9 \%) \\
\text { Tít. + pila }-6(54.5 \%) \\
\text { Apodo }-7(70 \%) \\
\text { Pila }-8(80 \%) \\
\text { Hipoc. }-2(100 \%) \\
\text { Tít. + apell. - } 1(33.3 \%)\end{array}$ & $\begin{array}{l}\text { N. común - } 8 \text { (12.9\%) } \\
\text { Apellido - } 1 \text { (33.3\%) } \\
\text { Tít. + apell. - } 1 \text { (33.3\%) }\end{array}$ \\
\hline
\end{tabular}

Tabla 5. Categoría de tratos nominales según la relación del referente con el hablante en Abajo. ${ }^{12}$

\begin{tabular}{l|l|l|l}
\multicolumn{1}{c|}{ Distancia } & \multicolumn{1}{|c|}{ Íntimo } & \multicolumn{1}{|c}{ Cercano } & \multicolumn{1}{c}{ Lejano } \\
Jerarquía & & & \\
\hline Superior & Título $-1(10 \%)$ & $\begin{array}{l}\text { N. común }-1(3.3 \%) \\
\text { Título }-6(60 \%) \\
\text { Título }+ \text { pila }-3(100 \%) \\
\text { Pila }-2(22.2 \%)\end{array}$ & Título -1 (10\%) \\
& & $\begin{array}{l}\text { Apodo }-2(22.2 \%) \\
\text { Apellido }-1(20 \%)\end{array}$ & \\
\hline
\end{tabular}

12. De dos casos de nombre común no fue posible identificar el tipo de relación. 


\begin{tabular}{|c|c|c|c|}
\hline Inferior & $\begin{array}{l}\text { N. común - } 2 \text { (6.7\%) } \\
\text { Pila - } 1 \text { (11.1\%) }\end{array}$ & $\begin{array}{l}\text { N. común - } 12(40 \%) \\
\text { Título - } 1(10 \%) \\
\text { Apodo - 3 (33.3\%) } \\
\text { Pila - 5(55.6\%) } \\
\text { Apellido- } 4(80 \%) \\
\text { Tít. + apell. - } 1 \text { (25\%) }\end{array}$ & $\begin{array}{l}\text { N. común - } 9 \text { (30\%) } \\
\text { Título - } 1 \text { (10\%) } \\
\text { Apodo - } 1(11.1 \%) \\
\text { Tít. + apell. - } 3(75 \%)\end{array}$ \\
\hline Igual & $\begin{array}{l}\text { N. común - } 1 \text { (3.3\%) } \\
\text { Pila - } 1 \text { (11.1\%) } \\
\text { Hipoc. - } 2 \text { (100\%) }\end{array}$ & $\begin{array}{l}\text { N. común - } 4(13.3 \%) \\
\text { Apodo - } 3(33.3 \%)\end{array}$ & \\
\hline
\end{tabular}

Tabla 6. Categoría de tratos nominales según la relación del referente con el hablante en Albañiles. ${ }^{13}$

\subsubsection{Tratamientos nominales y la valoración del destinatario}

Otro ámbito de comparación entre los tratamientos nominales en las tres obras literarias es su asociación con el valor positivo, negativo o neutro que atribuyen con ellos los hablantes a sus destinatarios, es decir, si los hablantes muestran por medio de ellos y en cada contexto enunciativo empatía, antipatía o imparcialidad hacia sus interlocutores.

De acuerdo con los datos en la tabla 7, son pocas las categorías de los tratos nominales que los hablantes asociaron con la valoración negativa. El nombre común destaca entre ellas. En las tres obras los porcentajes de su uso son los más altos, salvo en Abajo, en la que la frecuencia del nombre común fue mayor con la valoración positiva, pero solo por un ítem. En Bandidos y en $\mathrm{Al}$ bañiles el apodo también tuvo atribuciones negativas, pero solo en Albañiles alcanzó el porcentaje mayor. Ocurrieron también con valores negativos en estas dos obras usos de títulos, pero en muy baja frecuencia (en Albañiles, también, con apellido).

Salvo el nombre común, la mayor parte de las categorías de los tratos nominales tuvieron valoraciones positivas o neutras. En las tres obras, el título (solo o con nombre de pila) y el hipocorístico se usaron predominantemente con valor positivo, mientras que el nombre de pila y el uso del apellido se asociaron con mayor frecuencia con la neutralidad valorativa. El apodo, en cambio, fue el más variable: en Bandidos tuvo, sobre todo, usos positivos; en $A b a-$ jo, usos neutros y en Albañiles, usos negativos.

13. De un caso de nombre común no fue posible identificar el tipo de relación. 


\begin{tabular}{|c|c|c|c|}
\hline $\begin{array}{l}\text { VALOR } \\
\text { OBRA }\end{array}$ & Neutro & Positivo & Negativo \\
\hline Bandidos & $\begin{array}{l}\text { N. común - } 4 \text { (6.9\%) } \\
\text { Título - } 3(5.7 \%) \\
\text { Tít. + pila - } 1 \text { (3.4\%) } \\
\text { Pila - 26 (83.9\%) } \\
\text { Apellido - } 1(100 \%) \\
\text { Tít. + apell. - } 1(50 \%)\end{array}$ & $\begin{array}{l}\text { N. común - } 21 \text { (36.2\%) } \\
\text { Título - } 48(90.6 \%) \\
\text { Tít. + pila - } 28(96.5 \%) \\
\text { Apodo - } 10(90.9 \%) \\
\text { Pila - } 5(16.1 \%) \\
\text { Hipoc. - 6(100\%) } \\
\text { Tít. + apell. - } 1 \text { (50\%) }\end{array}$ & $\begin{array}{l}\text { N. común - } 33(56.9 \%) \\
\text { Título - } 2(3.8 \%) \\
\text { Apodo - } 1(9.1 \%)\end{array}$ \\
\hline Abajo & $\begin{array}{l}\text { N. común - } 15 \text { (24.2\%) } \\
\text { Título - } 1 \text { (12.5\%) } \\
\text { Tít. + pila - } 5 \text { (45.5\%) } \\
\text { Apodo - 8(80\%) } \\
\text { Pila - } 7 \text { (70\%) } \\
\text { Apellido-3 (100\%) } \\
\text { Tít. + apell. - 2(66.7\%) }\end{array}$ & $\begin{array}{l}\text { N. común - } 24 \text { (38.7\%) } \\
\text { Título - } 7(87.5 \%) \\
\text { Tít. + pila - 6(54.5\%) } \\
\text { Apodo - } 2(20 \%) \\
\text { Pila - } 3(30 \%) \\
\text { Hipoc. - } 2(100 \%) \\
\text { Tít. + apell. - } 1 \text { (33.3\%) }\end{array}$ & N. común - 23 (37.1\%) \\
\hline Albañiles & $\begin{array}{l}\text { N. común - } 4(13.3 \%) \\
\text { Título - } 3(30 \%) \\
\text { Pila - } 9(100 \%) \\
\text { Apellido - } 5(100 \%) \\
\text { Tít. + apell. - } 1 \text { (25\%) }\end{array}$ & $\begin{array}{l}\text { N. común - } 6 \text { (20\%) } \\
\text { Título - 6 (60\%) } \\
\text { Tít. + pila - 3 (100\%) } \\
\text { Apodo - } 3(33.3 \%) \\
\text { Hipoc. - } 2(100 \%) \\
\text { Tít. + apell. - } 2 \text { (50\%) }\end{array}$ & $\begin{array}{l}\text { N. común - } 20(66.7 \%) \\
\text { Título - } 1(10 \%) \\
\text { Apodo - 6 (66.7\%) } \\
\text { Tít. + apell. - } 1 \text { (25\%) }\end{array}$ \\
\hline
\end{tabular}

Tabla 7. Categorías de tratos nominales y sus valoraciones en cada obra.

\section{VARIABILIDAD DEL USO DE LOS TRATAMIENTOS NOMINALES}

Aunque no es posible tomar como base la frecuencia de uso de los tratamientos nominales en Bandidos, Abajo y Albañiles para establecer regularidades, los datos expuestos en el $\$ 4$ permiten confirmar algunas tendencias generales. Los factores correspondientes a las relaciones distantes, como el uso de usted, el trato no íntimo y el dirigirse a un superior, se asocian al empleo del título como categoría preferente del trato nominal. En el polo de las relaciones no distantes, como el tuteo, el trato de cercanía y el dirigirse a un no superior (sea inferior o igual), tiende a encontrarse el uso del nombre de pila y del hipocorístico.

En estas tendencias de la dimensión de la cercanía o distancia entre el hablante y el destinatario no parecen entrar los factores de la valoración que atri- 
buye el hablante al destinatario con los tratamientos nominales. Por ejemplo, el nombre común es de uso preferente cuando el hablante valora negativamente al destinatario, lo cual no tiene que ver con que su relación sea distante o cercana; tal parece que esta variable es transversal a dicho eje.

A pesar de estas tendencias, parece que la variabilidad del uso de los tratamientos nominales en sus diversas categorías es la regla en el corpus aquí analizado. Inclusive, podemos comprobar que los porcentajes en el $\$ 4$ no retratan el dinamismo de tal variación. En lo que sigue, hago una revisión cualitativa de las tres variables (la alternancia de los sistemas de segunda persona, el uso de títulos para desconocidos y la valoración), que ilustran el hecho de que un mismo tipo de trato nominal puede ser maleable según las circunstancias e impedir que se lo asocie indefectiblemente a un grupo de factores en específico.

\subsection{La alternancia del tuteo y del trato de usted con ciertos tratos nominales}

Se ha visto en el $\$ 4.2 .1$ que los tipos de los tratos nominales no se asocian categóricamente al trato de tú o de usted. Como ejemplo, tomo el vocativo compadre. Es conocido que este tratamiento puede usarse entre amigos o por una relación de padrinazgo (s.v. Santamaría; DEM; DLE). ${ }^{14}$ En México, a pesar de la cercanía entre los compadres, el trato suele ser de usted. En (4a) el diálogo se lleva a cabo entre compadres de pila: el licenciado Lamparilla, el padrino, y don Espiridión, padre del bautizado. En (4b) el tratamiento de compas -plural de compa, apócope de compañero o compadre- ${ }^{15}$ se da entre Evaristo -quien al calor de las copas ha estado coqueteando con Pancha- y don Jesús, el marido de Pancha. Aún en esa situación, se tratan de usted.

(4) Compadre y compa + usted

a. -¡Pero calle, compadre! ¿Qué tiene usted en el ojo, que no había reparado cuando le saludé?

-Percances del oficio, qué quiere usted. (Bandidos 1/39/490/1380813810)

14. Como vocativo empático, el uso cervantino de compadre se vincula con varones de grupos plebeyos (ver Iglesias Recuero $\$ 3.1$, en este mismo volumen).

15. En Bandidos, compa pareciera ser apócope de compañero, que es más frecuente; compadre, en esta obra, tiene más el sentido de compadre de pila. Sin embargo, en Abajo, es plausible que compa sea apócope de compadre, tal como lo consigna Langle (s.v. compa). 
b. -Don Evaristo, aquí tiene a mi marido Chucho -dijo Pancha. -Ya me lo había dicho don Jesús -contestó Evaristo tendiendo la mano a don Chucho, que éste apretó.

-Conque compas y a almorzar -respondió Evaristo-, que las chalupitas se ponen tiesas si se enfrían. -Al mismo tiempo tendió su jorongo en el suelo e hizo seña a Pancha para que se sentara-. Y los demás amigotes que vengan, llámelos -le dijo a Chucho. (Bandidos 1/19/217/5814-5820)

No obstante, el trato de usted entre compadres no es la regla. En Abajo, Demetrio Macías y Anastasio Montáñez se tratan con el apelativo compadre, pero en su uso de la segunda persona predomina el eje del poder. Si Demetrio, superior, se dirige a Anastasio, su inferior, lo tutea y Anastasio, a su vez, se dirige a Demetrio con usted, como sucede en (5a). En el mismo ejemplo, otro subalterno de Demetrio, la Codorniz, se dirige a Venancio, el barbero, con tuteo y con la apócope compa, en una relación de igualdad. En (5b) la interacción entre Anastasio y Demetrio se mantiene con el trato jerárquico: Anastasio trata de usted a Demetrio y este lo tutea, ambos con los vocativos compadre.

(5) Compadre y compa + tú/usted

a. -¿Por qué no llama al curro pa que lo cure, compadre Demetrio? -dijo Anastasio Montáñez al jefe, que a diario sufría grandes calosfríos y calenturas-. Si viera, él se cura solo y anda ya tan aliviado que ni cojea siquiera.

Pero Venancio, que tenía dispuestos los botes de manteca y las planchuelas de hilas mugrientas, protestó:

-Si alguien le pone mano, yo no respondo de las resultas.

-Oye, compa, ¡pero qué dotor ni qué naa eres tú!... ¿ ¿Voy que ya hasta se te olvidó por qué veniste a dar aquí? -dijo la Codorniz.

-Sí, ya me acuerdo, Codorniz, de que andas con nosotros porque te robaste un reloj y unos anillos de brillantes -repuso muy exaltado Venancio. (Abajo 1/10/127-128/0968-0983)

b. -Si vieras qué bien explica las cosas el curro, compadre Anastasio -dijo Demetrio, preocupado por lo que esa mañana había podido sacar en claro de las palabras de Luis Cervantes.

-Ya lo estuve oyendo -respondió Anastasio-. La verdad, es gente que, como sabe leer y escribir, entiende bien las cosas. Pero lo que a mí no se me alcanza, compadre, es eso de que usted vaya a pre- 
sentarse con el señor Natera con tan poquitos que semos. (Abajo $1 / 14 / 141 / 1347-1356)$

Otro ejemplo de alternancia de tuteo y trato de usted con un mismo tratamiento nominal es el apellido. En los datos en $\$ 4.2 .1$ no se observa una tendencia clara del apellido con alguno de los sistemas de segunda persona. De hecho, en una misma interacción, se presenta alternancia. En (6), Demetrio ordena a Valderrama que le cante una canción, primero con trato de usted y después, en un acto insistente, con tuteo. En (7), el ingeniero Zamora se dirige al Chapo con su apellido: en (7a) con tuteo y en (7b) con usted.

(6) Apellido + usted/tú

Por la tarde hubo peleas de gallos. Demetrio y sus principales jefes se sentaron bajo el cobertizo del portalillo municipal, frente a una plazuela inmensa, poblada de yerbas, un kiosco vetusto y podrido y las casas de adobe solitarias.

-iValderrama! -llamó Demetrio, apartando con fastidio los ojos de la pista-. Venga a cantarme El enterrador.

Pero Valderrama no le oyó [...]

-;Valderrama! -volvió a gritar Demetrio. Cántame El enterrador. (Abajo 3/03/247/4176-4194)

(7) Apellido + tú/usted

a. INGENIERO ZAMORA (violento): ¡Son un par de inútiles! Qué piensan que están levantando, ¿una casa de muñecas?

CHAPO: Nosotros cumplimos órdenes, ingeniero.

INGENIERO ZAMORA: No me vengas con cuentos, Álvarez, no te conozco de ayer. (Albañiles 2/039-040/084/0829-0832)

b. CHAPO (a facinto): Ya párate, tú.

JACINTO (al ingeniero Zamora): Que los otros lo digan, ingeniero. INGENIERO ZAMORA: Saque a este imbécil de aquí, Álvarez. Sáquelo. (Albañiles 2/065-068/085/0864-0867)

\subsection{Titulos y términos de parentesco para el trato a desconocidos}

En ocasiones, los títulos o términos de parentesco se emplean para dirigirse a desconocidos, de tal manera que tales tratamientos, aunque de origen pueden inclinarse a los polos de la intimidad o la cercanía y la distancia formal, 
en estos usos llegan a tener connotaciones de respeto, consideración o desprecio. En (8a) Demetrio se dirige a un peón al que apenas conoce con vocativos empáticos, uno de ellos, bijo. El peón lo trata con el título patrón. En (8b) los indios agradecen a Pancha que les convide las sobras del pulque con el vocativo madrecita, sin realmente conocerla, atribuyéndole superioridad. En (8c), la dueña de la embarcación emplea don para apelar a un pasajero desconocido que le provoca desconfianza, acerca de lo cual, Payno explica en nota al pie: “Así llama la gente del pueblo de México a las personas cuyo nombre de bautismo no sabe, o que mira con cierto desprecio" (Bandidos vol. 1, n. 31, 365).

(8) Títulos y términos de parentesco

a. Demetrio reconoció al peón cojitranco y le preguntó:

$-¿$ ¿Cuánto ganas diario, amigo?

-Diez y seis centavos, patrón... [...]

-Desquitas bien el sueldo, bijo -le interrumpió Demetrio con mansedumbre. (Abajo 2/10/215-216/3368-3376)

b. De cuando en cuando Pancha les pasaba un tecomate con restos de pulque blanco y de sangre de conejo. Los indios devolvían la vasija vacía, y besando la mano de Pancha, le decían:

-Dios se lo pague, madrecita. (Bandidos 1/19/218/5852-5855)

c. Como había cerrado la noche, Cecilia encendió la linterna que siempre llevaba en la popa, y se dirigió con ella hacia donde estaba el pasajero.

-Oiga, don -le dijo con desembarazo y poniéndose el farolillo cerca de la cara-, ¿querría usted volverse a México? Aquí están sus cinco pesos y uno más por la dejación.

$-¿$ Es decir, que usted me echa fuera?

-De echarlo, no; pues que recibí los cinco pesos y aunque soy mujer tengo palabra, sino a la buena, por favor.

-Por favor es otra cosa -le dijo Evaristo, clavando su mirada en Cecilia-, hasta la vida daría por usted, pero por favor le pido que me deje hacer el viaje, se me haría mucha dejación en quedarme. (Bandidos 1/30/365-366/10163-10186)

\subsection{Variación en la valoración del destinatario del tratamiento nominal}

Un tratamiento nominal no implica, necesariamente, una actitud positiva o negativa. De hecho, un trato nominal despectivo puede usarse con sentido fami- 
liar y no despectivo $(\$ 2)$ o, a la inversa, uno positivo con sentido negativo. Un ejemplo de ello son los usos de curro en Abajo. Existen diversas acepciones de $\mathrm{cu}$ rro, ${ }^{16}$ pero las más cercanas al significado de este nombre común en Abajo son las de "caballero" o "señor" (s.v. Ramos i Duarte), "señorito", "señor bien puesto" (s.v. Santamaría) o "catrín remilgado" (s.v. Brambila Pelayo/Páez Brotchie), que los revolucionarios emplean para dirigirse despectivamente a Luis Cervantes, un joven estudiante de medicina de piel blanca que se une a la Revolución. ${ }^{17}$ En (9a) el uso de curro es negativo, cuando Cervantes se encuentra sometido por los revolucionarios y es todavía un desconocido de quien estos se burlan. En (9b), Demetrio, el revolucionario que lo tenía capturado, ya emplea curro para dirigirse a él con cierta empatía, después de que este le ha estado curando una herida. En (9c) Camila se dirige a Cervantes con curro, estando enamorada de él y, en (9d), Venancio, un barbero al que Cervantes le ve vocación de médico, decide abandonar el vocativo curro por el nombre de pila, en diminutivo, Luisito (lo cual también destaca Olea Franco 195), por elevar su relación con él a la de una amistad.

(9) Valoraciones de curro

a. -Llévenselo..., y si quiere confesarse, tráiganle un padre...

Anastasio, impasible como siempre, tomó con suavidad el brazo de Cervantes.

-Véngase pa acá, curro...

Cuando después de algunos minutos vino la Codorniz ensotanado, todos rieron a echar las tripas.

-¡Hum, este curro es repicolargo! -exclamó la Codorniz-. (Abajo 1/07/120/0769-0777)

b. -iQué se me hace que usté está enamorado, curro! -le dijo Demetrio, bromista, un día, después de la curación y comenzando a encariñarse con él. (Abajo 1/10/129/1023-1025)

c. Luis Cervantes, distraído, con su indiferencia envalentonó a Camila, que habló al fin:

-Oye, curro... Yo quería icirte una cosa... Oye, curro; yo quiero que me repases $L a$ Adelita... pa... ¿A que no me adivinas pa qué?... Pos

16. Por ejemplo, de baja estatura (s.v. Amaro Gamboa; Patrón Peniche; Palomar de Miguel; Santamaría) o hipocorístico de Francisco (s.v. Palomar de Miguel; Santamaría).

17. Al respecto, Olea Franco también anota, acerca del uso de curro en Abajo: "En este caso, el término «curro» no posee una permanente intención positiva, ya que quienes designan así a Cervantes también desean enfatizar su condición ajena respecto de ellos, o sea, el hecho de que no pertenece a su grupo social y, por tanto, no es apto para su modo de vida" (Olea Franco 194). 
pa cantarla muncho, muncho, cuando ustedes se vayan, cuando ya no estés tú aquí..., cuando andes ya tan lejos, lejos..., que ni más te acuerdes de mí... (Abajo 1/11/131/1081-1088)

d. -¡Admirable! ¡Tiene usted un bellísimo talento!

-No lo tengo malo -repuso Venancio convencido-; pero mis padres murieron y yo no pude hacer carrera.

-Es lo de menos. Al triunfo de nuestra causa, usted obtendrá fácilmente un título. Dos o tres semanas de concurrir a los hospitales, una buena recomendación de nuestro jefe Macías..., y usted, doctor... ¡Tiene tal facilidad, que todo sería un juego!

Desde esa noche, Venancio se distinguió de los demás dejando de llamarle curro. Luisito por aquí y Luisito por allí. (Abajo 1/10/130/ 1044-1054)

En cambio, amigo, originalmente con sentido empático, puede usarse en situaciones negativas. ${ }^{18}$ En (10a), como vocativo en una amenaza de un revolucionario a un soldado federal y, en (10b), en actos intimidantes del inspector Munguía en su interrogatorio al Chapo Álvarez.

(10) Amigo, con valoración negativa

a. -Anastasio, préstame tu reata; mi cabestro se revienta con este gallo... Pero, ahora que lo pienso mejor, no... Amigo federal, te voy a matar de una vez; vienes penando mucho. Mira, los mezquites están muy lejos todavía y por aquí no hay telégrafo siquiera para colgarte de algún poste. [...]

-iNo, amigo federal! -dijo lentamente retirando el arma y volviéndola a su funda-, no te quiero matar todavía... Vas a seguir como mi asistente... ¡Ya verás si soy hombre de mal corazón! (Abajo 2/09/212/3273-3278 y 2/09/213/3291-3294)

b. MUNGUÍA: Estoy enterado de sus trinquetes, amigo. Usted tiene un negocio de materiales de construcción. El local está situado en la avenida Patriotismo número...

CHAPO (interrumpiendo): ¿Eso es un delito?

MUNGUía: El material que vende es robado.

CHAPO: ¿Tiene testigos?

18. Para ejemplos cervantinos de amigo en actos amenazadores de la imagen, ver Iglesias Recuero (\$4.3.2) en este mismo volumen. 
MUNGUIA: Tengo testigos.

CHAPO (irónico): Si usted lo dice...

MUNGUía: Su situación es muy comprometida, amigo Álvarez.

Don Jesús era su cómplice. (Albañiles 2/006-012/082/0779-0788)

En el español de México, el adjetivo canijo es injurioso, con el significado de "mala persona" (s.v. Ramos i Duarte; Santamaría; DLE; DEM; $D A$ ); ha llegado a gramaticalizarse como interjección (s.v. Santamaría; $D E M$ ) y llega a extender su significado a persona "lista, aguda, inteligente" (s.v. $D A$ ), acepción que es la que se muestra en (11), con valoración positiva, al reconocerle Jacinto, albañil, al Chapo cuánto lo ha beneficiado.

(11) Canijo, con valoración positiva

CHAPO: Empezaste temprano, Jacinto. ¿No invitas?

JACINTO: Seguro que invito. A ti te invito lo que quieras y cuando quieras ¡Te debo la vida, Chapo! Todo lo que soy te lo debo a ti. A ver, quién otro iba a ayudarme como tú me has ayudado. Quién otro iba a sacarme de mi pueblo. Nadie. Quién iba a darme chamba. Nadie. Quién iba a hacerme socio en sus movidas. Nadie más que tú, canijo Chapo... Y qué bien está saliendo la acarreada, ¿no?; ni quien se las huela. ¡A listo no hay quien te gane!... ¿Para cuándo calculas que pueda empezar mi casita? (Albañiles 2/286-287/096/1201-1208)

En cambio, un título profesional que, como se ha visto en el $\$ 4$, suele asociarse al trato formal con valoración positiva, se combina en (12) con un adjetivo insultante. En el fragmento, el inspector Munguía resume, al final de Albañiles, que cada uno de los personajes en escena tenía motivos para asesinar a don Jesús. Al inculpar a Federico (El Nene, hijo del ingeniero Zamora y también ingeniero), cita el vocativo imaginario a este emitido por don Jesús en una especie de cita directa, con el desdén reflejado en su risa burlona.

(12) Ingeniero, con un insulto

MUNGUÍA (afiebrado, dirigiéndose a ellos): ¡Asesinos! (Señala a Patotas:) Fue usted. No pensaba hacerlo, pero el viejo se puso necio y lo amenazó. Usted había ido a la bodega sólo por la cartera del Nene, porque necesitaba esos tres mil mugrosos pesos. (Señala a Federico:) Porque necesitaba entregar las relaciones a su padre y porque sólo yendo a contar tabique por tabique, bulto por bulto, mosaico por 
mosaico, podía rectificar sus cálculos. No quería matarlo. Fue la risa del viejo: ingeniero estúpido, ingeniero estúpido, ingeniero estúpido. (Albañiles 2/377/104-105/1470-1481)

\section{ConClusión}

La tarea de identificar la sistematicidad lingüística de los tratamientos nominales se abre en varias vertientes: en el estudio de las formas y estructuras internas de estos sintagmas nominales, de las unidades morfológicas y léxicas que las conforman, y en el estudio del uso que de ellas hacen los hablantes, lo cual requiere de la selección de variables contextuales y situacionales determinadas. Aunque con esta segunda perspectiva se amplía el campo de observación del fenómeno, resulta necesario controlar el grado de variabilidad de su ocurrencia para explicar la posible influencia de las variables seleccionadas en los tipos de tratamiento nominal. La obtención de los datos por medio de la aplicación de encuestas a una muestra determinada de hablantes responde a esta necesidad de control. No obstante, con esta técnica se corre el riesgo de no registrar el dinamismo del uso de los tratamientos en la interacción verbal. Una de las opciones para resolver este problema, además del levantamiento de corpus de interacciones reales, es acudir a obras literarias que contengan pasajes dialógicos.

En el corpus de tratamientos nominales obtenido de las tres obras literarias mexicanas de este estudio no ha sido posible identificar tendencias claras del uso de los tipos de tratamientos nominales en función de los sistemas de segunda persona ( $t u ́$ y usted), las relaciones interpersonales de simetría y asimetría y las valoraciones que los hablantes atribuyen a los destinatarios de los tratamientos nominales. De hecho, se ha observado en el dinamismo dialógico que un mismo tratamiento nominal puede emplearse con varios de los factores de las variables independientes, sin restricciones claras. En cambio, la única coincidencia entre los tratamientos nominales de las tres obras es la categoría gramatical de su núcleo sintagmático. Convendría extraer más datos de otras obras literarias de otros autores coetáneos, primero, para observar si se delinean tendencias menos variables y, segundo, descartar si los hallazgos de esta investigación no dependen de rasgos estilísticos o, incluso, diacrónicos.

$\mathrm{Al}$ respecto, en la continuación de la investigación, valdrá la pena tomar en cuenta la uniformidad del género literario de las fuentes seleccionadas, pues el hecho de que dos de las obras aquí estudiadas sean novelas, frente a la ter- 
cera, que es teatro, puede estar influyendo en los resultados. Otro aspecto que podría arrojar más luz respecto de la buscada sistematicidad en el uso de los tratamientos nominales es la observación del uso de cada forma, según los tipos de actos de habla, así como de determinadas estrategias de cortesía verbal y de actividad de la imagen (face); por ejemplo, los usos exclusivamente de don, señor (a), etc. y sus variantes morfosintácticas, en función de un grupo de variables determinadas. En otras palabras, observar cómo combina un hablante determinadas formas de los sistemas de tratamiento gramaticales y nominales con factores específicos de las demás variables para conseguir los diversos grados de cercanía/distancia y poder/solidaridad. ${ }^{19}$

\section{OBRAS CITADAS}

Alba de Diego, Vidal, y Jesús Sánchez Lobato. "Tratamiento y juventud en la lengua hablada. Aspectos sociolingüísticos". Boletín de la Real Academia Española 60 (1980): 95-130.

Alonso-Cortés, Ángel. "Las construcciones exclamativas. La interjección y las expresiones vocativas". Bosque y Demonte. Vol. 3. 3993-4050.

Amaro Gamboa, Jesús. Vocabulario del uayeísmo en la cultura de Yucatán. 2 vols. Mérida, Yuc.: Universidad Autónoma de Yucatán, 1987.

Azuela, Mariano. Los de abajo. 1920. Ed. Víctor Díaz Arciniega. México D.F.: FCE/El Colegio Nacional/UAM, 2015.

Báez Pinal, Gloria Estela. "Vitalidad y tradición de hipocorísticos empleados en la ciudad de México: 1955-1999: un estudio comparativo". Anuario de Letras 40 (2002): 241-65.

Bosque, Ignacio, y Violeta Demonte (dirs.). Gramática descriptiva de la lengua española. 3 vols. Madrid: Espasa Calpe, 1999.

Boyd-Bowman, Peter. "Cómo obra la fonética infantil en la formación de los hipocorísticos". Nueva Revista de Filología Hispánica 9.4 (1955): 337-66.

Boyd-Bowman, Peter. "Los nombres de pila en México desde 1540 hasta 1950". Nueva Revista de Filología Hispánica 19.1 (1970): 12-48.

Brambila Pelayo, Alberto Magno, y Luis Páez Brotchie. Lenguaje popular en Falisco. Guadalajara, Jal.: s. e., 1957.

19. Agradezco a Pedro Eduardo Hernández Fuentes, becario de investigación, su apoyo en la elaboración de las bases de datos para este estudio. También agradezco a las coordinadoras de esta sección y a los evaluadores del texto sus observaciones y sugerencias atinadas. 
Brown, Roger, y Marguerite Ford. "Address in American English”. Language in Culture and Society: A Reader in Linguistics and Antbropology. Ed. Dell Hymes. New York: Harper \& Row, 1964. 234-44.

Brown, Roger, y Albert Gilman. "The Pronouns of Power and Solidarity". Style in Language. Ed. Thomas A. Sebeok. Cambridge, Mass: The MIT Press, 1961. 253-76.

Brown, Penelope, y Stephen Levinson. Politeness: Some Universals in Language Use. 1978. Cambridge: Cambridge Up, 1987.

Bühler, Karl. Sprachtheorie. Stuttgart: Gustav Fischer, 1934.

Calderón Campos, Miguel. "Los elementos nominales en el sistema de tratamiento del español de Andalucía durante la Restauración (1875-1931)". Hummel, Kluge y Vázquez Laslop. 551-70.

Cepeda Ruiz, Cristal Yeseidy. Formas pronominales y fórmulas nominales de tratamiento en el español de la Ciudad de México. 2019. Universidad Nacional Autónoma de México, tesis doctoral. <https://ru.dgb.unam.mx/handle/ DGB_UNAM/TES01000796975>.

DA: Asociación de Academias de la Lengua Española. Diccionario de americanismos. Madrid: Santillana, 2010. 27 de enero de 2020. <https://www.asale.org/recursos/diccionarios/damer>.

DEM: Lara Luis Fernando, dir. Diccionario del español de México. México: El Colegio de México, 2010. 27. <dem.colmex.mx>.

Díaz Arciniega, Víctor. "Los de abajo, cien años después”. Mariano Azuela. Los de abajo. Ed. Víctor Díaz Arciniega. México D.F.: FCE/El Colegio Nacio$\mathrm{nal} / \mathrm{UAM}, 2015$. 9-90.

DLE: Real Academia Española. Diccionario de la lengua española. 23. ${ }^{a}$ ed. Madrid: Espasa-Calpe, 2014. 27 de enero de 2020. < dle.rae.es>.

Espinal, M. ${ }^{a}$ Teresa. "On the Structure of Vocatives". Sonnenhauser y Noel Aziz Hanna. 109-32.

Estrada, Juan Bernardo. "La formación de los hipocorísticos en el español de México". Anuario de Letras. Lingüística y Filología 2.2 (2014): 5-33.

Fernández, Mauro, y Katharina Gerhalter. "Pronombres de segunda persona y fórmulas de tratamiento en español: una nueva bibliografía (18672016)". LinRed. Lingiüstica en la Red 14 (2016-2017) 25 de junio de 2020. $<$ http://www.linred.es/informacion_pdf/LR_informacion20_20170219. pdf $>$.

Fernández Leborans, M. ${ }^{a}$ Jesús. "El nombre propio". Bosque y Demonte. Vol. 3. 77-128. 
Fontanella de Weinberg, M. ${ }^{a}$ Beatriz. "Sistemas pronominales de tratamiento usados en el mundo hispánico". Bosque y Demonte. Vol. 3. 1399-425.

Hammermüller, Gunther. "Evolución de las formas de tratamiento del español medieval hasta el siglo XVI". Hummel, Kluge y Vázquez Laslop. 507-29.

Helincks, Kris. "La forma de tratamiento nominal buevón en Iquique (Chile): análisis empírico de conversaciones cotidianas informales". Onomázein 32 (2015): 132-51.

Herrera Lima, María Eugenia, y José Francisco Mendoza. “Antropónimos en el español de la ciudad de México. Tradición y novedad". Anuario de Letras 31 (1993): 431-96.

Hummel, Martin, Bettina Kluge y María Eugenia Vázquez Laslop, eds. Formas y fórmulas de tratamiento en el mundo hispánico. México, D.F.: El Colegio de México/Karl Franzens Universität Graz, 2010.

Jakobson, Roman. "Shifters, Verbal Categories, and the Russian Verb". 1957. Selected Writings, II: Word and Language. The Hague/Paris: Mouton, 1971. 130-47.

Jiménez de Báez, Yvette. "Los de abajo de Mariano Azuela: escritura y punto de partida”. Nueva Revista de Filología Hispánica 40.2 (1992): 843-74.

Kim Lee, Uh Sung. El uso de tú y usted en el español de la Ciudad de México. 1989. Universidad Nacional Autónoma de México, tesis de maestría. $<$ https://repositorio.unam.mx/contenidos/452405>.

Kleinknecht, Friederike. "Mexican güey -from Vocative to Discourse Marker: A Case of Grammaticalization?”. Sonnenhauser y Noel Aziz Hanna. 235-68.

Langle, Arturo. Vocabulario, apodos, seudónimos, sobrenombres y hemerografía de la Revolución. México, D.F.: Universidad Nacional Autónoma de México, 1966.

Leñero, Vicente. Los albañiles. 1969. Vicente Leñero. Teatro completo. Vol. 1. Ciudad de México: FCE, 2008. 49-106.

Lope Blanch, Juan M. Cuestionario para la delimitación de las zonas dialectales de México. México, D.F.: El Colegio de México, 1970.

Lope Blanch, Juan M., ed. Atlas lingüístico de México, 4: Morfosintaxis. México, D.F.: El Colegio de México, 1996.

Miquel i Vergés, María Eugenia. "Fórmulas de tratamiento en la Ciudad de México". Anuario de Letras 3 (1963): 35-86.

Morera, Marcial. Cortesía, apodos e hipocorísticos en español: fundamentos lingüísticos. Madrid: Arco Libros/La Muralla, 2017. 
NGLE: Real Academia Española y Asociación de Academias de la Lengua Española. Nueva gramática de la lengua española. 2 vols. Madrid: Espasa, 2009.

Noel Aziz Hanna, Patrizia, y Barbara Sonnenhauser. "Vocatives as functional performance structures". Sonnenhauser y Noel Aziz Hanna. 283-304.

Olea Franco, Rafael. La lengua literaria mexicana: de la Independencia a la Revolución (1816-1920). Ciudad de México: El Colegio de México, 2019.

Palacios, Niktelol. "Algunos marcadores discursivos característicos del habla de los adolescentes mexicanos". Iztapalapa. Revista de Ciencias Sociales y Humanidades 53 (2002): 225-47.

Palacios Martínez, Ignacio M. “«Help me Move to That, Blood»: A CorpusBased Study of the Syntax and Pragmatics of Vocatives in the Language of British Teenagers". Fournal of Pragmatics 130 (2018): 33-50.

Palomar de Miguel, Juan. Diccionario de México. México, D.F.: Panorama, 1991.

Patrón Peniche, Prudencio. Léxico yucateco: barbarismos, provincialismos y mayismos. México: Talleres Tipográficos "Tenoxtitlán”, 1932.

Payno, Manuel. Los bandidos de Río Frío. Ed. Manuel Sol. 3 vols. Ciudad de México: Secretaría de Cultura, 2016.

Pedroviejo Esteruelas, Juan Manuel. "Formas de tratamiento pronominales y nominales en el siglo Xx: análisis de dos obras de teatro: Historia de una escalera y Bajarse al moro". Interlingüística 14 (2003): 829-44.

Ramírez Gelbes, Silvia, y Andrea Estrada. "Vocativos insultivos vs. vocativos insultativos: acerca del caso de boludo". Anuario de Estudios Filológicos 26 (2003): 335-53.

Ramos i Duarte, Feliz. Diccionario de mejicanismos: colección de locuciones i frases viciosas con sus correspondientes criticas $i$ correcciones fundadas en autoridades de la lengua; máximas, refranes, provincialismos i remoques populares de todos los estados de la República Mejicana. Méjico: Imprenta de Eduardo Dublán, 1895.

Rendle-Short, Johanna. “ «Mate» as a Term of Address in Ordinary Interaction”. Fournal of Pragmatics 42 (2010): 1201-18.

Robles, Humberto E. “Aproximaciones a Los albañiles de Vicente Leñero”. Revista Iberoamericana 36.73 (1970): 579-99.

Santamaría, Francisco J. Diccionario de mejicanismos, razonado, comprobado con citas de autoridades; comparado con el de americanismos y con los vocabularios provinciales de los más distinguidos diccionaristas hispanoamericanos. México, D.F.: Porrúa, 1974. 
Schlickers, Sabine. "Las novelas de Vicente Leñero". Doscientos años de narrativa mexicana: siglo XX. Ed. Rafael Olea Franco. México, D.F.: El Colegio de México, 2010. 363-84.

Scollon, Ron, Suzanne Wong Scollon y Rodney H. Jones. Intercultural Communication: A Discourse Approach. 1995. Malden: Wiley-Blackwell, 2012.

Sonnenhauser, Barbara, y Patrizia Noel Aziz Hanna (eds.). Vocative! Addressing between System and Performance. Berlin: Mouton de Gruyter, 2013.

Szmetan, Ricardo. "Los albañiles, de Vicente Leñero, dentro de las novelas de detectives". Confluencia. Revista Hispánica de Cultura y Literatura 4.2 (1989): 67-71.

Vázquez Laslop, María Eugenia, y Leonor Orozco. "Formas de tratamiento del español en México”. Hummel, Kluge y Vázquez Laslop. 247-69. 

SECCIÓN MISCELÁNEA 
